\title{
Vaccination in pregnancy against pertussis and seasonal influenza: key learnings and components from high-performing vaccine programmes in three countries: the United Kingdom, the United States and Spain
}

Théophile Baïssas ${ }^{1}$, Florence Boisnard² ${ }^{2}$ Inmaculada Cuesta Esteve ${ }^{3}$, Marta Garcia Sánchez ${ }^{4}$, Christine E. Jones ${ }^{5}$, Thierry Rigoine de Fougerolles ${ }^{6}$, Litjen Tan ${ }^{7}$, Olivier Vitoux ${ }^{6}$ and Christina Klein ${ }^{*^{*}}$

\begin{abstract}
Background: Pertussis and seasonal influenza are responsible for significant maternal, neonatal, and infant morbidity and mortality, but vaccine coverage rates (VCR) for both pertussis (administered as a tetanus, diphtheria, acellular pertussis [Tdap] vaccination) and seasonal influenza in pregnancy remain generally low. Only a small number of countries, including Spain, the United Kingdom (UK), and the United States (US), have high Tdap and seasonal influenza VCRs in pregnancy. The purpose of this study was to identify the key factors that contributed to the high VCRs observed in these countries.
\end{abstract}

Methods: The experience from both Tdap and seasonal influenza vaccination programmes during pregnancy were documented in Spain, the UK, and the US using a three-step approach. A literature review yielded 157 publications, and a further 117 documents were selected through desk research. A published five-pillar VCR framework for influenza was amended to evaluate the specific contributing factors leading to high Tdap and seasonal influenza VCRs among pregnant women.

Results: The analysis identified components that contributed to higher VCR in pregnant women across three different healthcare systems in Spain, UK, and US. The combination of several key interventions in each country led to a rapid increase in VCR that reached near-optimal levels (i.e. 75\% for seasonal influenza) within a few years. As well as inclusion in national immunisation programme and vaccine reimbursement, key components that were identified included the mobilisation of health authorities, prenatal care Healthcare Professionals (HCP) and scientific societies, the inclusion of vaccination in antenatal medical guidance, the provision of educational material to $\mathrm{HCPS}$, and a strong disease awareness driven by recent pertussis outbreaks in each country.

Conclusions: Although there is no simple, universal solution to improving sub-optimal VCRs, the list of components identified in this study from three countries with high-performing Tdap and seasonal influenza vaccination

*Correspondence: christina.klein@sanofi.com

2 Sanofi Pasteur, 14, Espace Henry Vallée, 69007 Lyon, France

Full list of author information is available at the end of the article

(c) The Author(s) 2021. Open Access This article is licensed under a Creative Commons Attribution 4.0 International License, which permits use, sharing, adaptation, distribution and reproduction in any medium or format, as long as you give appropriate credit to the original author(s) and the source, provide a link to the Creative Commons licence, and indicate if changes were made. The images or other third party material in this article are included in the article's Creative Commons licence, unless indicated otherwise in a credit line to the material. If material is not included in the article's Creative Commons licence and your intended use is not permitted by statutory regulation or exceeds the permitted use, you will need to obtain permission directly from the copyright holder. To view a copy of this licence, visit http://creativecommons.org/licenses/by/4.0/. The Creative Commons Public Domain Dedication waiver (http://creativeco mmons.org/publicdomain/zero/1.0/) applies to the data made available in this article, unless otherwise stated in a credit line to the data. 
programmes provides a basis for public health and medical stakeholders in other countries to define strategies to successfully implement national vaccination programmes for pregnant women.

Keywords: Immunisation, Influenza, Maternal, Pregnancy, Prenatal, Pertussis, Tdap, Vaccine coverage rate

\section{Background}

Vaccination against seasonal influenza and pertussis in pregnancy has proven effective in reducing the burden of seasonal influenza among pregnant women and their infants as well as reducing the severity of pertussis in young infants [1-4]. Pregnant women and children particularly those less than 6 months of age are considered to be priority risk groups for influenza since they experience increased rates of outpatient visits, hospitalizations, and deaths $[5,6]$. However, influenza vaccination is only recommended from 6 months of age and therefore cannot provide protection to the youngest, most vulnerable infants. Even though the evidence on the burden of pertussis in vulnerable adults is growing, severe pertussis infection mostly affects infants between birth and 6 months of age [7, 8]. Infants under 6 months of age accounted for $42.3 \%$ of all pertussis-related hospitalizations in 2018 among children in the United States (US) [9]. A modelling study by the World Health Organization (WHO) highlighted that there were 85,900 estimated pertussis-related deaths in infants younger than 1 year in 2014 worldwide [10]. With no pertussis vaccines licensed to protect new-borns in their first weeks of life, pertussis vaccination in pregnancy remains the most effective method of providing protection during this vulnerable period.

In 2005, the WHO recommended influenza vaccination for all pregnant women. Due to the severity of 2009 H1N1 pandemic infections among pregnant women, this group was recommended as the highest priority group for inclusion in influenza immunisation programmes [11, 12]. This not only provides protection of the mother from severe disease but also protects the infant in the first months of life, before they are eligible to receive influenza vaccination. However, while influenza vaccination during pregnancy was gradually adopted in most highand middle-income countries, many low-income countries have yet to include it in their routine immunisation programmes [13-17]. Furthermore, many existing programmes reach an influenza vaccine coverage rate (VCR) that is sub-optimal compared with the WHO target rate of $75 \%$ for the elderly and other risk groups [18-21]. In nine EU/EEA Member States, VCR ranged from 0.5 to 59\% (median 25\%) in 2016-17. The remaining EU/EEA Member States, where influenza vaccination is recommended for pregnant women, reported that vaccination coverage was not monitored for this population [22].
In 2015, the WHO recommended pertussis vaccination in pregnancy as the most cost-effective additional strategy for preventing disease in infants too young to be vaccinated [23]. The routine use of combination pertussis, diphtheria, and tetanus vaccines (Tdap) means that maternal immunity is boosted against these infections in addition to the provision of passive neonatal protection. Currently, pertussis vaccination during pregnancy is recommended by the national or supranational health authorities in more than 55 countries globally [24, 25]. Yet, despite growing adoption and funding under national immunisation programmes, many countries consistently fail to achieve among pregnant women a VCR as high as in childhood vaccination programmes. Only a few high-income countries successfully vaccinate a majority of pregnant women, such as Spain, the United Kingdom (UK), or the US with respective VCRs of $84 \%$, $71 \%$, and $57 \%$ in 2019 [26-29].

The WHO has developed several tools to support countries considering the introduction of pregnancy vaccination programmes or to improve the implementation of existing programmes. These include a toolkit for Influenza Vaccine Post-Introduction Evaluations and a dedicated field guide for the implementation of pregnancy vaccination in Latin America [30, 31]. However, actionable information for a successful programme of vaccination in pregnancy remains limited.

This study aimed to provide a thorough analysis of the programmatic components that contribute to the success of influenza and Tdap vaccination programmes in pregnancy based on practices in high-income countries achieving high VCR.

\section{Methods}

\section{Methodological basis}

A range of methodologies were considered to analyse the performance of influenza and Tdap vaccination programmes in pregnancy. From WHO models on vaccine hesitancy to practical taxonomies for the determinants of vaccine uptake such as the 5As (Access, Affordability, Awareness, Acceptance, Activation), several methodologies have been developed to comprehend the outcome of vaccination programmes [32, 33]. Kassianos et al. study was selected as a methodological backbone for this study given its emphasis on identifying actionable programmatic and policy components contributing to high seasonal influenza VCR amongst high-income countries 
with adult vaccination programmes [34]. Based on an analysis of the vaccination programmes in the US, UK, Canada, and Australia, this methodological framework consists of five pillars structuring 42 components as contributing factors of high VCR among older adults, some of which are also relevant to vaccination in pregnancy. Since the factors contributing to vaccination in pregnancy may differ significantly from those among older adults, and since our study also includes Tdap vaccination, the five-pillar structure and list of components from Kassianos et al. was adapted and expanded based on data gathered in three relevant benchmark countries (Spain, UK, and US). A three-step data collection approach was thus used in the considered countries including a detailed review of published literature using an academic literature database, a manual search of official sources, and a complementary search of grey literature.

\section{Benchmark country selection}

For this analysis focusing on vaccination in pregnancy in high-income countries, Spain, the UK and the US were selected due to their pioneering approach to establishing both influenza and pertussis pregnancy vaccination programmes, their success in improving uptake, and the availability of annual VCR measurements by their respective health authorities to analyse the components that contributed to VCR growth. Even though other high-income countries than the three considered have developed pregnancy vaccination programmes they did not fulfil these three selection criteria and were thus not selected for this study. Furthermore, the US, with a mostly privatized and fragmented healthcare system, the UK with a public and centralized system, and Spain with a public and decentralized system were chosen as three illustrative examples to encompass different health system architectures. Since VCR values are published for England and Wales in separate reports, only England values are considered in this study to analyse trends given that the nation holds $84 \%$ of the UK population compared to $5 \%$ for Wales [35].

\section{Data collection}

The data collection relied both on global and countryspecific published literature, and a manual search of official sources as well as grey literature available online (Table 1). An Embase search was performed to identify relevant published articles. Search terms were refined through Emtree subject headings searches and structured in three categories: Disease, Vaccination, and Population. Disease search terms in each category are detailed in Additional file 1 (Table SI 1). The search was performed for each country and publications from 2010 to 2020 were considered. All the titles and abstracts identified
Table 1 Sources of information utilized in the data collection

\begin{tabular}{|c|c|c|c|c|}
\hline & $\begin{array}{l}\text { United } \\
\text { States of } \\
\text { America }\end{array}$ & $\begin{array}{l}\text { United } \\
\text { Kingdom }\end{array}$ & Spain & Total \\
\hline \multicolumn{5}{|c|}{ Review of published literature using Embase } \\
\hline Embase search yield & 1252 & 834 & 117 & 2203 \\
\hline Selected articles & 86 & 33 & 23 & 192 \\
\hline \multicolumn{5}{|c|}{ Manual search of official sources } \\
\hline Health authority reports & 23 & 14 & 18 & 55 \\
\hline \multicolumn{5}{|c|}{ Complementary search of grey literature } \\
\hline $\begin{array}{l}\text { Healthcare professional \& } \\
\text { lay public communication } \\
\text { material }\end{array}$ & 22 & 16 & 17 & 55 \\
\hline Market reports & 2 & 1 & 3 & 6 \\
\hline Others & 0 & 1 & 0 & 1 \\
\hline
\end{tabular}

through these searches were screened using a patient, intervention, comparison, outcome (PICO) search strategy (Table SI 2), followed by a screening of the full text. As a result, 86 articles were selected for the US, 33 articles for the UK, and 23 articles for Spain (Table 1).

Additional manual searches of health authority (HA) websites and reports, leading scientific societies and research groups position papers, healthcare professional (HCP) associations training documentation, lay public communication material, and key conferences were conducted to limit potential publication bias in this study (Table 1). Such sources were also used to identify official VCR data and to evaluate the measures and actions implemented over time to improve VCR.

\section{Elaboration of the pregnancy VCR framework}

Based on the published literature, official documents and communication materials identified in the three countries considered, all components described as contributing to the performance of pregnancy vaccination programmes were listed. Since VCR is a multifactorial variable and as the impact of some components may take time to materialize, the components were not selected purely on the direct quantitative impact on VCR, but rather based on whether they were described as a key contributor of higher vaccine uptake among pregnant women. The framework was consequently adapted to vaccination in pregnancy by matching identified components with those of Kassianos et al. framework to either add, edit or replace them in the relevant pillars.

\section{Results}

The implementation of the pregnancy vaccination programmes in Spain, the UK, and the US has led to coverage rates ranging from $44 \%$ to $61 \%$ for influenza 


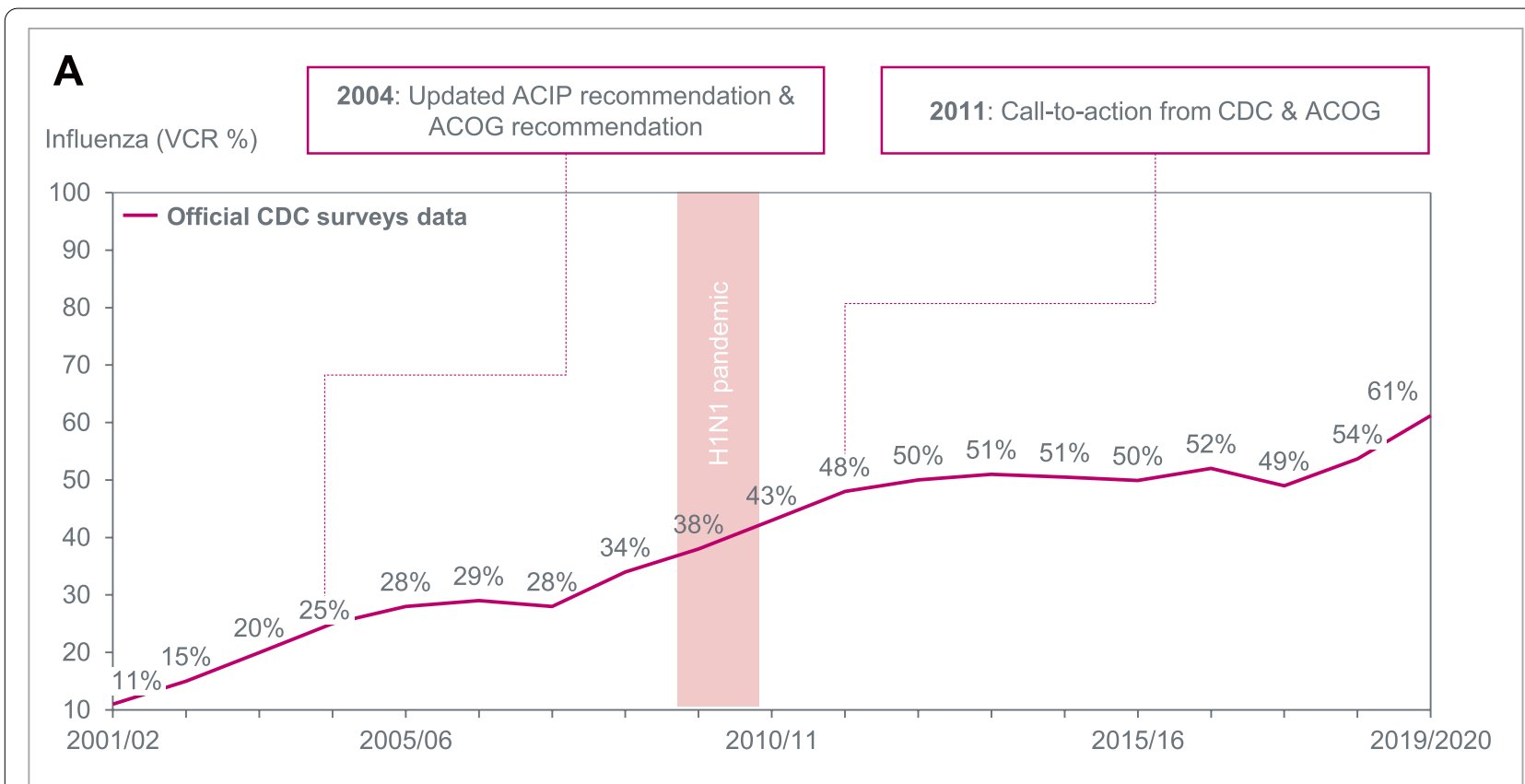

ACIP: Advisory Committee on Immunization Practices, ACOG: American College of Obstetricians and Gynecologists, CDC: Centers for Disease Control, VCR: Vaccine Coverage Rates

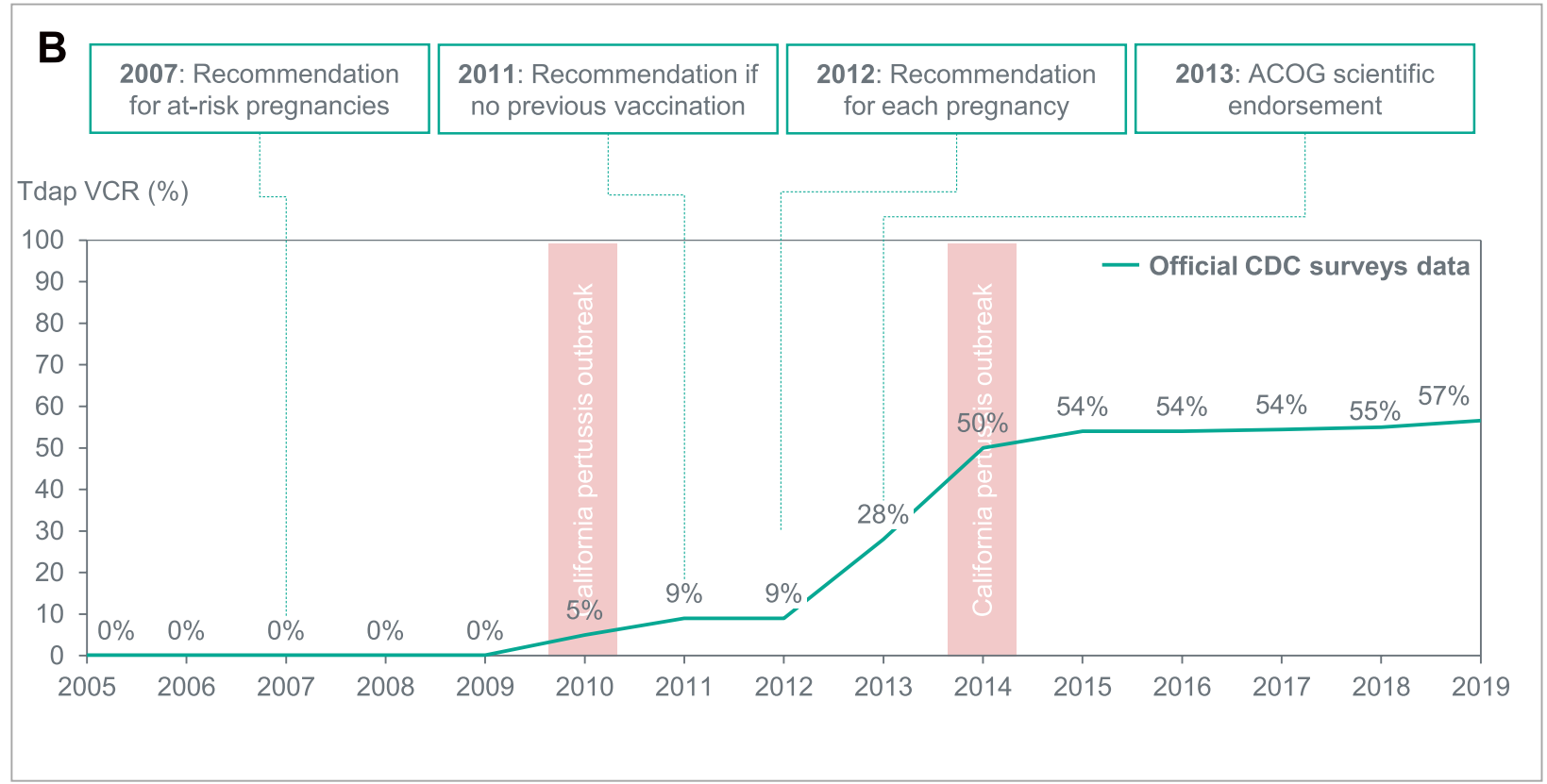

ACOG: American College of Obstetricians and Gynecologists, CDC: Centers for Disease Control, Tdap: Tetanus, diphtheria, acellular pertussis, VCR: Vaccine Coverage Rates

Fig. 1 Evolution of VCR for influenza (2001-2019) and Tdap (2005-2019) among pregnant women in the US. A Influenza. B Tetanus, diphtheria, acellular pertussis (Tdap)

and from 57 to $84 \%$ for Tdap (Figs. 1, 2, 3). In each country, VCR growth rate has generally been slower for seasonal influenza vaccination than for Tdap, despite earlier healthy authority recommendations and funding of vaccination costs [36]. For pertussis vaccination, the VCR improved to levels above $50 \%$ over a two-to-three year period in each country (Figs. 1, 2, 3). 


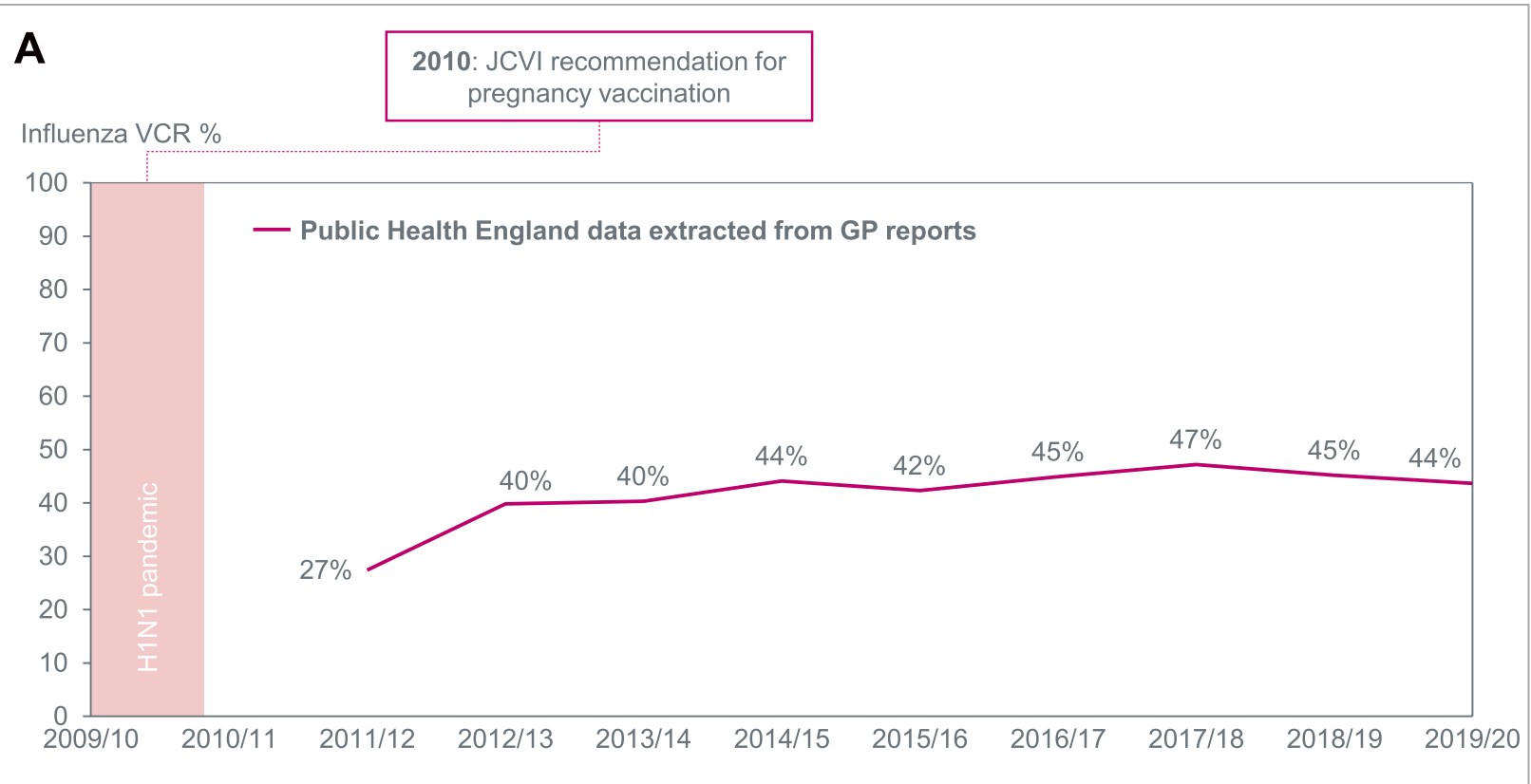

GP: General Practitioner, JCVI: Joint Committee on Vaccination and Immunisation, VCR: Vaccine Coverage Rates

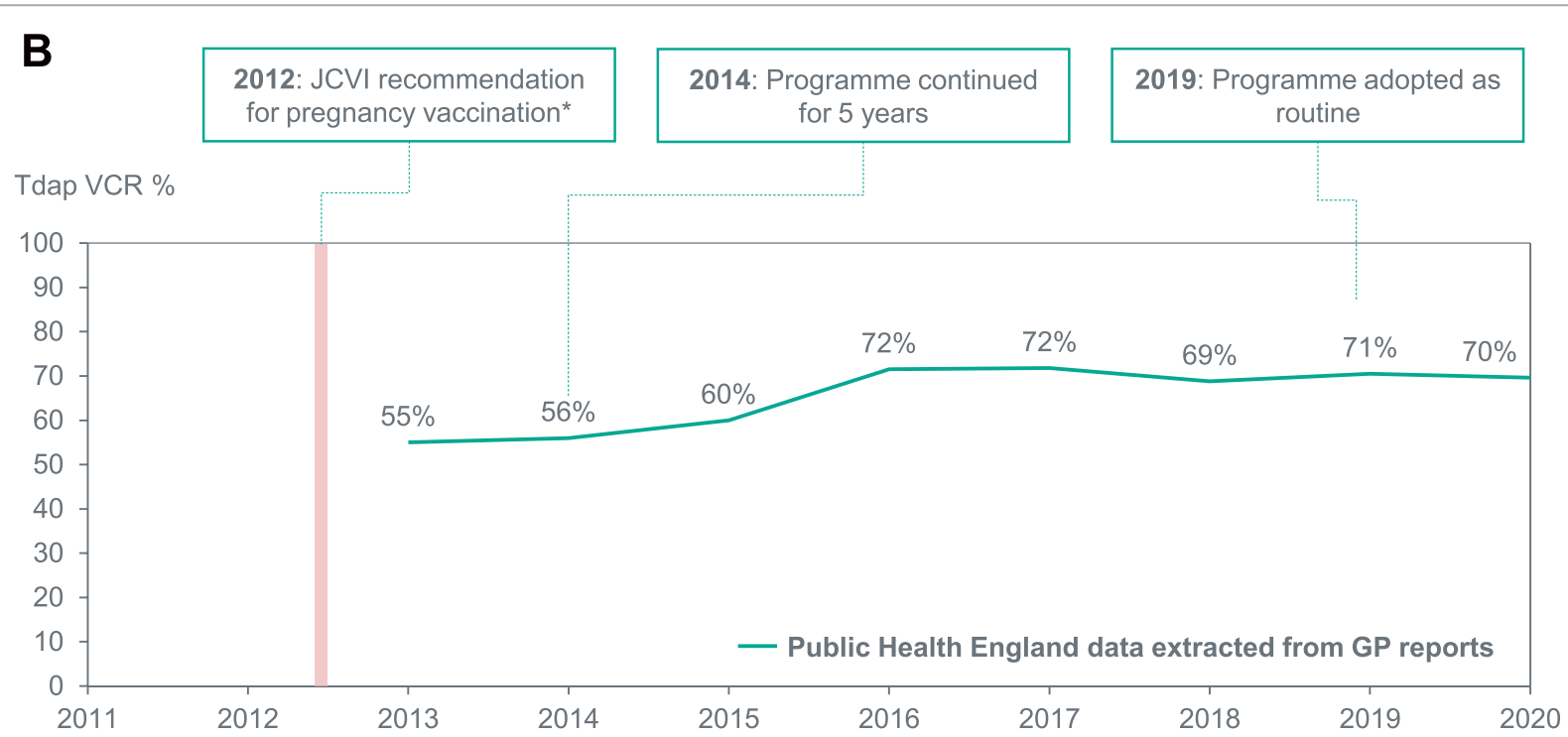

${ }^{*}$ Chief Medical Officer announcement of pregnancy vaccination programme following rise of number of pertussis cases

GP: General Practitioner; JCVI: Joint Committee on Vaccination and Immunisation, Tdap: Tetanus, diphtheria, acellular pertussis, VCR: Vaccine Coverage Rates

Fig. 2 Evolution of VCR for influenza (2011-2020) and Tdap (2013-2020) among pregnant women in the UK. A Influenza. B Tetanus, diphtheria, acellular pertussis (Tdap) 


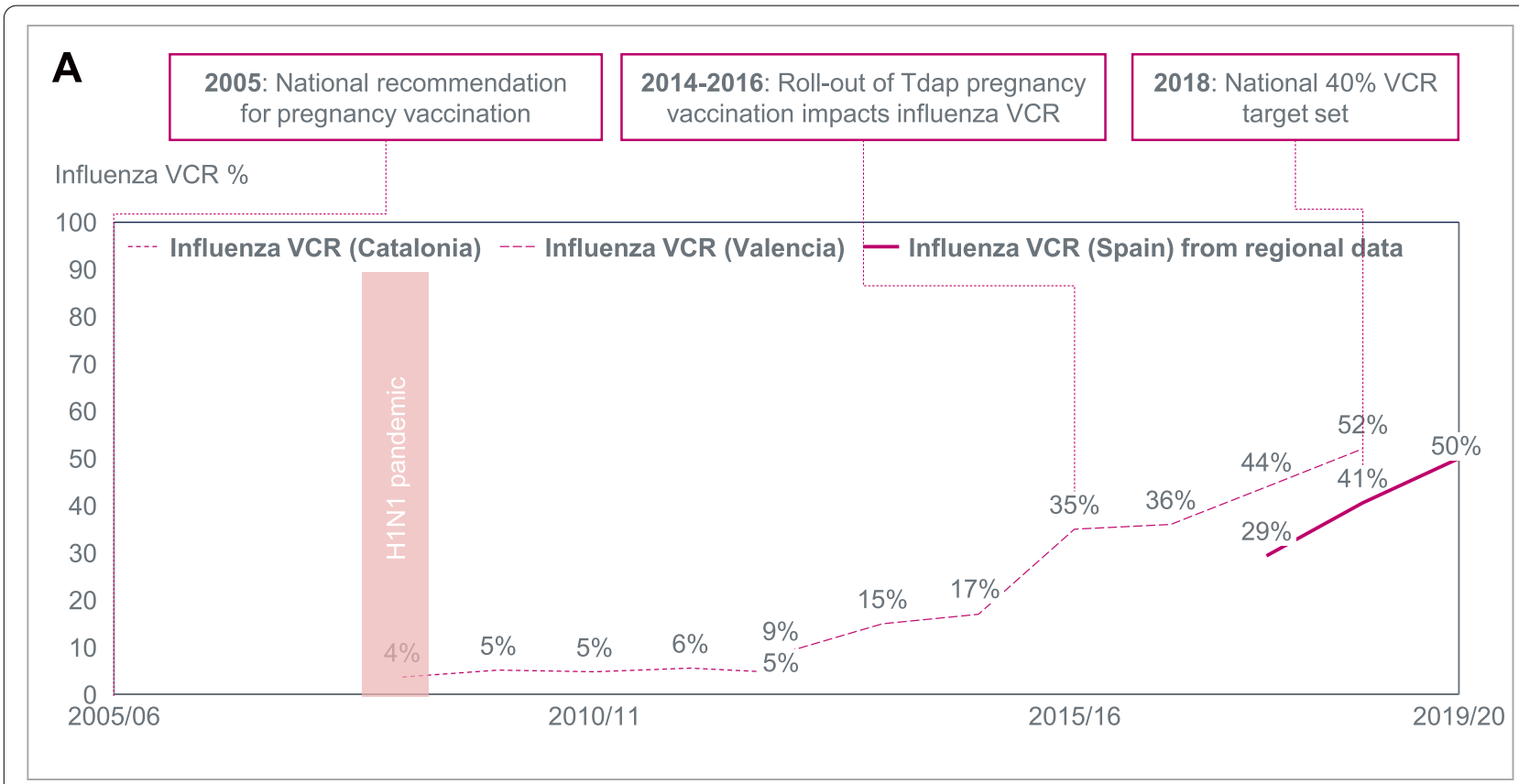

Tdap: Tetanus, diphtheria, acellular pertussis; VCR: Vaccine Coverage Rates

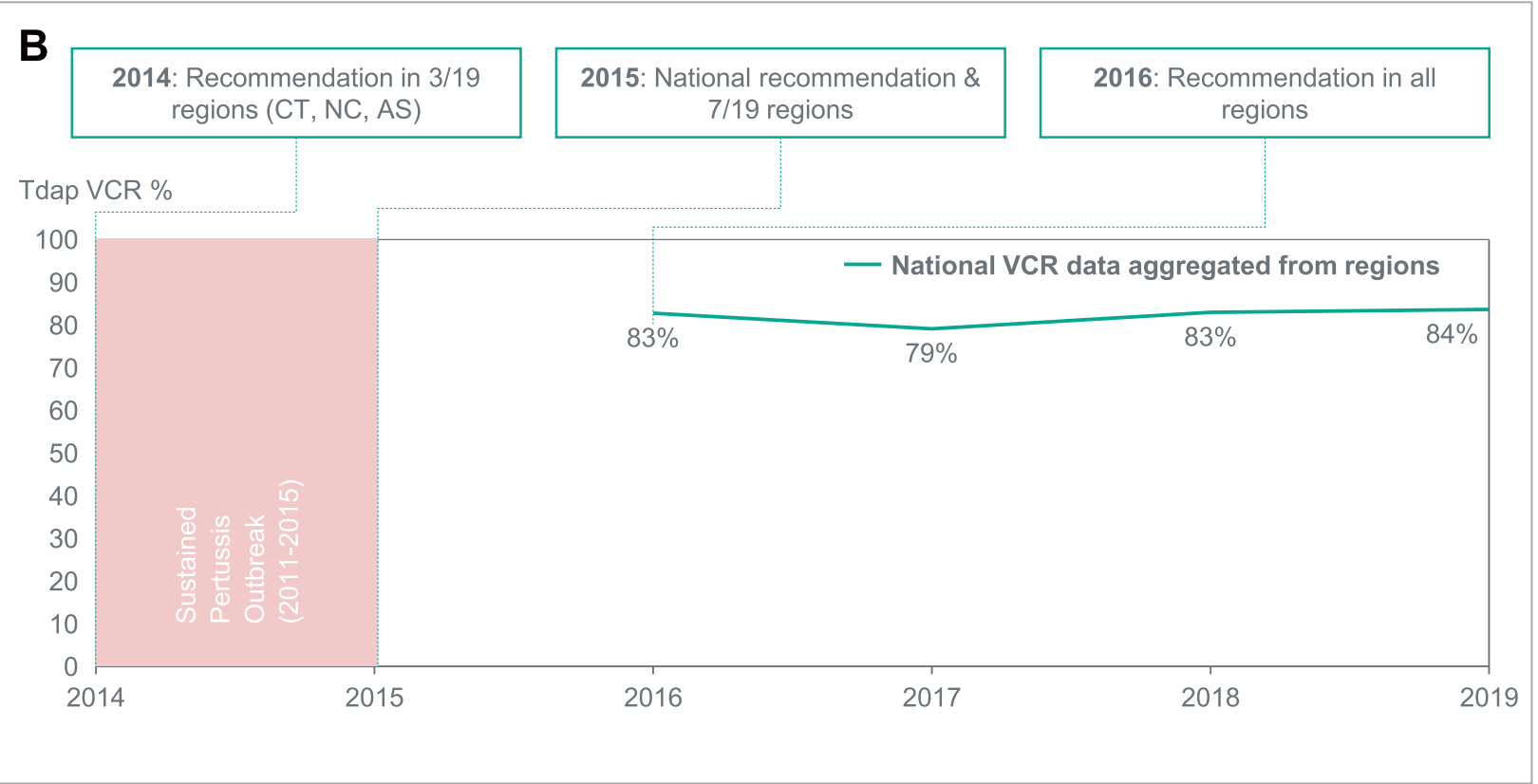

AS: Principality of Asturias, CT: Catalonia, NC: Chartered Community of Navarre, Tdap: Tetanus, diphtheria, acellular pertussis, VCR: Vaccine Coverage Rates

Fig. 3 Evolution of VCR for influenza (2008-2020) and Tdap (2016-2019) among pregnant women in Spain. A Influenza. B Tetanus, diphtheria, acellular pertussis (Tdap) 


\section{The United States - seasonal influenza vaccination in pregnancy}

Seasonal influenza VCR data was collected from nationwide survey data published in several Mortality and Morbidity Weekly Reports (MMWR) articles and from Kennedy et al. [29, 37, 38]. The US pioneered influenza vaccination in pregnancy with a recommendation for at-risk pregnant women dating back to 1966, which was updated by the Advisory Committee on Immunisation Practices (ACIP) to all pregnant women in their third trimester in 1995, and expanded to the second trimester in 1997 [39-41]. By the early 2000s the VCR reached 10 to $20 \%$ (Fig. 1). In 2004, the recommendation was updated to include all trimesters in accordance with WHO guidance [11, 42, 43]. Despite an endorsement by the American College of Obstetricians and Gynecologists (ACOG) in 2004, the VCR remained below 30\% until 2007 [44]. The burden associated with the A/H1N1 2009 pandemic led to an increased mobilization among scientific societies, practitioners and lay public alike [45]. As a result, the VCR reached $50 \%$ by 2012 and over $60 \%$ in 2019. Nonetheless, current values fall short of the $80 \%$ target set by Healthy People 2020, an initiative that develops sets of objectives to improve the health of all Americans [46].

\section{The United States - pertussis (Tdap) vaccination in pregnancy}

Tdap VCR was gathered from nationwide survey data from the CDC and MMWR articles [28, 29, 47]. A recommendation for the vaccination of at-risk pregnant women with Tdap was first issued in 2007 but the overall VCR remained close to 0\% (Fig. 1). Following the 2010 pertussis outbreak in California, a recommendation was issued by the state to expand Tdap vaccination to both at-risk and healthy pregnant women [48]. This was followed by the ACIP which issued a recommendation in 2011 to vaccinate pregnant women with no prior history of Tdap vaccination, updated in 2012 to all pregnancies $[49,50]$. This move was actively endorsed by scientific societies and key HCP associations such as the ACOG in 2013 [51]. Guidelines were cascaded to their members and the medical care organizations also followed suit by including Tdap vaccination in the medical protocol of pregnant women [52]. The impact on VCR was substantial, increasing from $9 \%$ to $50 \%$ within 2 years, and was also driven by the high public awareness at the time fed by communication from multiple stakeholders around pertussis prevention (Fig. 1). Since 2014 however the VCR measured by CDC surveys has plateaued at 55\%, suggesting, as for influenza vaccination, persisting issues with regard to access to vaccination, HCP engagement and vaccine acceptance [29].

\section{The United Kingdom - seasonal influenza vaccination in pregnancy}

In the UK, VCR data was collected from PHE (Public Health England) which extracts and aggregates data from General Practitioners (GPs) electronic reports [53]. PHE issued a recommendation for influenza vaccination during pregnancy in 2010, following a Joint Committee on Vaccination and Immunisation (JCVI) decision, in response to the severity of the $\mathrm{A} / \mathrm{H} 1 \mathrm{~N} 1 \mathrm{pdm} 09$ strain among pregnant women $[54,55]$. This decision was corroborated by the cost-effectiveness of the intervention [56, 57]. PHE and the NHS (National Health Service) updated their guidance, training kits, and awareness materials accordingly to support GPs. As a result, VCR quickly reached $27 \%$ in the first season, $2011 / 2012$, and $40 \%$ in the $2012 / 2013$ seasons (Fig. 2). However, the limited vaccine effectiveness and persisting myths around the risks of vaccination have contributed to a plateau of the VCR at sub-optimal levels around $45 \%$ since the 2014/15 season, markedly below the WHO and EU target of $75 \%$ (Fig. 2).

\section{The United Kingdom - pertussis (Tdap) vaccination in pregnancy}

For Tdap pregnancy vaccination, the VCR increase occurred faster due to high disease awareness among healthcare professionals and lay public alike. The national pertussis outbreak in 2012 caused the deaths of 14 non-immunized infants [58]. In a context of intense media noise on the large increase in cases and deaths reported by the Health Protection Agency (HPA), the JCVI adopted the recommendation for Tdap vaccination during all pregnancies [59-62]. A rapid roll-out of the guidance, training resources and awareness material for GPs led by PHE and the NHS followed, leading to a VCR above $50 \%$ in the first year [63] (Fig. 2). As this programme was proven to be safe, highly efficient, and cost-effective, it was extended for a further 5 years in 2014 [64]. The recommendation of the vaccination timing was expanded in 2016 to include weeks 16-32 of pregnancy and obstetricians, gynecologists, and midwives were increasingly mobilized in addition to the GPs. The programme was eventually adopted as routine in 2019 with VCR having reached a plateau around $70 \%[63,65]$. (Fig. 2).

\section{Spain - seasonal influenza vaccination in pregnancy}

Health authorities in Spain included pregnant women in their second or third trimester in the risk groups for influenza vaccination as early as 2005 [66]. This was rapidly extended to all trimesters starting in 2006 in regions such as Catalonia [67, 68]. Yet, influenza VCR remained consistently low among pregnant women, at $\sim 5 \%$, as 
highlighted in several regional studies [67, 69] (Fig. 3). The roll-out of the Tdap pregnancy vaccination programme had a positive impact on influenza vaccination of pregnant women and synergies between the programmes led to a significant increase in influenza VCR, ultimately reaching the national VCR target of $40 \%$ for pregnant women in the 2018/2019 season [69-72] (Fig. 3). VCR data aggregated from regional reporting by the Ministry of Health since 2017/18 has shown a sharp increase [70,73].

\section{Spain - pertussis (Tdap) vaccination in pregnancy}

The rapid adoption of Tdap vaccination during pregnancy was driven by a public health response to the rising number of pertussis cases and deaths in infants below 3 months of age due to a "permanent outbreak situation" from 2011 to 2015 [74]. In light of the recommendation from the JCVI in 2012 in the UK, scientific societies including the Spanish Association of Paediatrics (AEP) played an important role in highlighting the burden of pertussis to national and regional health authorities $[75,76]$. This led to the adoption of new recommendations by three pioneering regions (Catalonia, Asturias, and Navarra). By the end of 2016, all regions had introduced a Tdap pregnancy vaccination program. An analysis rapidly confirmed the effectiveness of the approach with the Red Nacional de Vigilancia Epidemiológica (RENAVE) highlighting a decreased incidence of pertussis cases in infants under 1 year of age and especially those under 3 months of age [74]. Since 2016, Tdap VCR data aggregated from regional reporting available from the Ministry of Health has been consistently at or above 80\% since 2016 [70] (Fig. 3).

\section{The five-pillar VCR framework and adaptation of the list of components}

As part of this analysis, a set of key components driving vaccine uptake was identified. The pre-existing five-pillar framework for influenza VCR was utilised to organise a list of components tailored to the specificities of seasonal influenza and Tdap vaccination in pregnancy [34]. The 5-pillar structure was confirmed as applicable and the pillars were adapted as follows:

1. Health Authority accountability and strengths of the pregnancy vaccination programme.

2. Facilitated patient access to vaccination.

3. Healthcare professional accountability and engagement.

4. Awareness of the burden and severity of diseases.

5. Belief in the benefits of pregnancy vaccination.

A total of 45 components were identified as relevant contributing factors to the successful roll-out of a pregnancy vaccination programme (Table 2). Of these, 15 components were unchanged from the previous framework, 14 were adapted, 16 were added as specific to the context of vaccination in pregnancy, and 13 removed as not applicable [34]. The national health authority recommendation, the absence of financial barriers to getting immunized, and a structured infectious disease surveillance network are applicable to maternal immunisation programme and were amongst the components that remained unchanged. The components that were adjusted to the context of vaccination in pregnancy include but are not limited to multiple HCPs (Ob-Gyns, GPs, midwives, nurses, pharmacists) being allowed to vaccinate, training of HCPs on pregnancy vaccination by multiple stakeholders, and adapted HCP training material for pregnancy vaccination. The new components specifically identified for the vaccination of pregnant women include the mention of immunization in the pregnant women medical protocol, a clear delineation of $\mathrm{HCP}$ roles and responsibilities, and the availability of adapted awareness material at maternal care providers.

\section{Results of the five-pillar assessment across the three countries}

The adjusted five-pillar VCR framework of 45 components was used as a methodological basis to analyse the factors that contributed to the successful programmes in the US, the UK and Spain. There was significant variability across the three countries, which is likely to be attributable to the structural differences in the healthcare architecture and strategy applied for the commissioning of the vaccination programme in pregnancy. Overall, the UK had the highest number of components fully implemented (38 out of 45), followed by Spain (31 out of 45), and the US ( 25 out of 45 ). In the UK, five components were deemed as partially implemented, compared with 11 in Spain and 18 in the US. Finally, two components were missing in both the UK and the US, and three in Spain (Fig. 4). These differences mainly concerned components relating to the role of VCR targets and monitoring, the convenience of the patient journey, and the importance of the different HCPs involved in recommending and delivering vaccination in pregnancy. The three countries also differed in how adequate training was provided to HCPs as well as the incentivization for vaccinating pregnant women. (Additional file 1, Figs. SI 1-3) Finally, while the framework applied to both influenza and pertussis, some nuances between the two must be considered. The VCR of pertussis vaccination in pregnancy was higher than for influenza in all three countries, possibly because this programme emphasizes the indirect protection of the infant from the potentially serious complications of pertussis in infancy. 


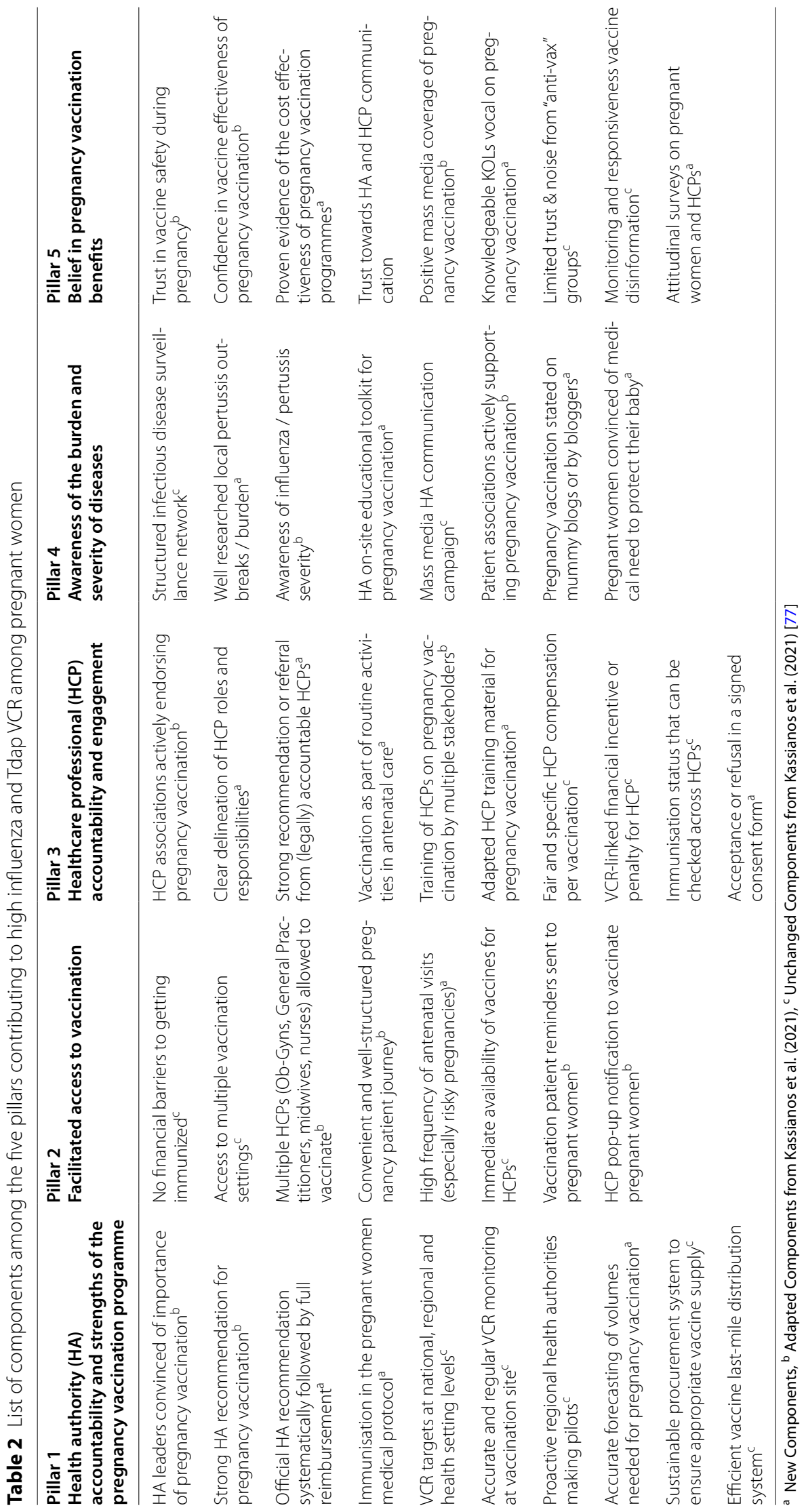




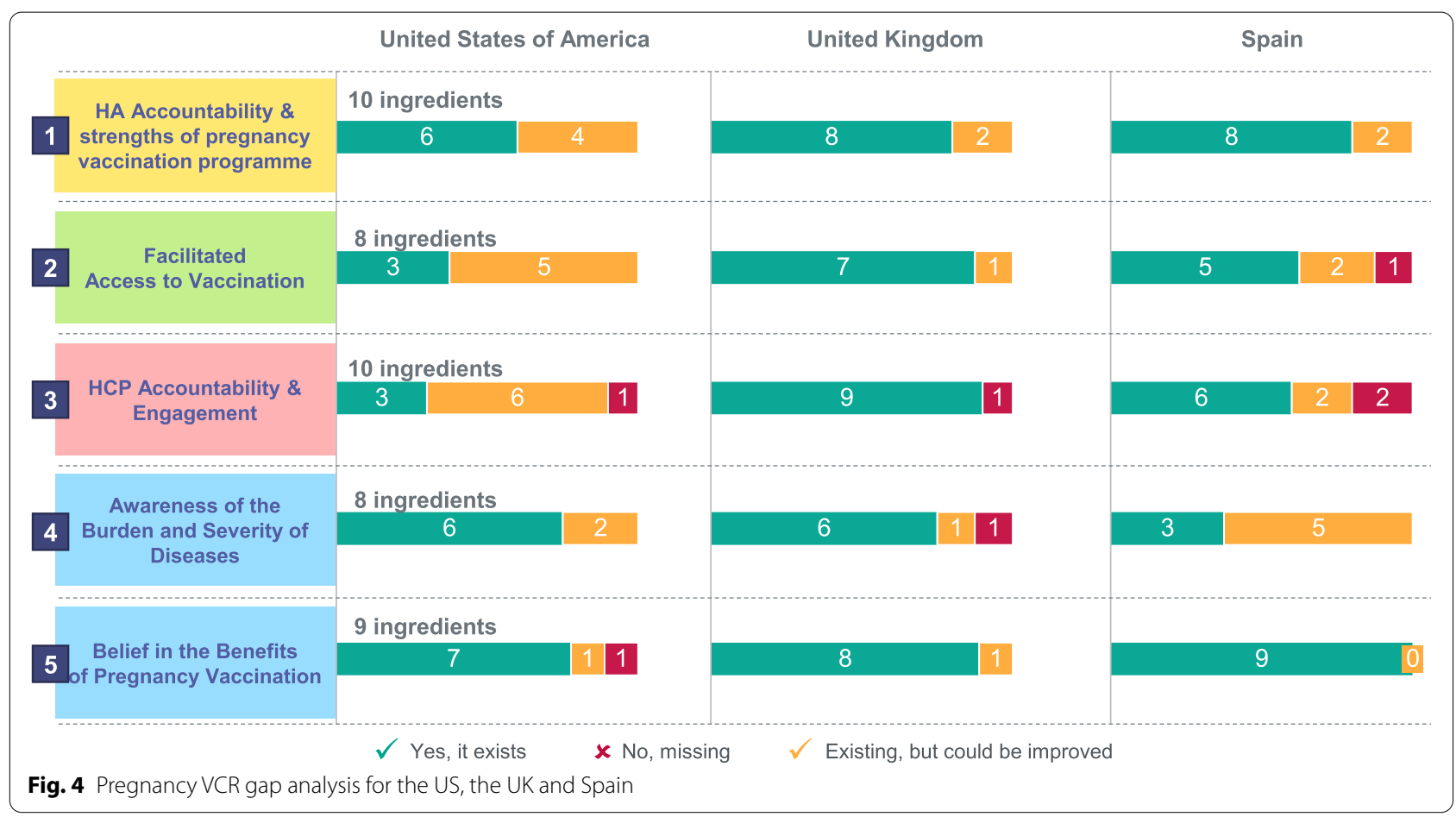

Although there are benefits of influenza vaccination in pregnancy for infants, these may be less well-known or communicated to pregnant women. Finally, the seasonal nature of influenza vaccination has practical implications which must be considered for both the timing of vaccine administration and the identification of pregnant women.

\section{Discussion}

The Pregnancy VCR framework developed in this study is designed to facilitate the implementation of vaccination programmes for pregnant women by providing a list of possible components structured in five pillars. The onus would remain with an individual country to determine the applicability and relevance of a specific intervention. The significant variability of the results indicates that having a successful programme does not rely on having all components but rather finding the right combinations of components that are tailored to each country's context and healthcare system architecture.

The US, the UK, and more recently Spain, have monitored VCR following the introduction of their pregnancy vaccination programmes, enabling the analysis of the evolution of vaccine uptake and the components associated with VCR growth. The vaccination programmes analysed owe a large part of their success to proactive health authorities (Pillar 1). Beyond establishing an official vaccination recommendation and reimbursement, supporting programme implementation is critical. In the UK, PHE and the NHS were instrumental in producing
$\mathrm{HCP}$ training material and information for patients when commissioning the immunisation programme [78]. In Spain, the proactive development of such communication materials by some regional health authorities is likely to have contributed to the higher performance of some regions such as Cantabria and Comunitat Valenciana, both achieving Tdap VCR above $90 \%$ among pregnant women $[26,66]$. In the US, given the higher diversity of stakeholders, a multi-stakeholder approach with frequent and coordinated calls to action from the CDC and the leading scientific societies were essential to ensure the continued uptake of pregnancy vaccinations. For instance, the 2020 maternal task force reinforced the importance of a one-voice message from key HCP associations involved in the care of pregnant women $[79,80]$. Another key lever that health authorities can act upon is to include pregnancy vaccination as part of the routine antenatal medical protocol [81]. Furthermore, continuous and accurate monitoring of VCR is a key element for the evaluation of a programme after its introduction and can be complemented by setting official VCR targets.

Facilitated access to vaccination (Pillar 2) with minimum physical, geographic, and financial barriers stands out as critical. Beyond offering vaccination free of charge, providing pregnant women with the opportunity to be vaccinated in convenient settings including GP clinics, community antenatal clinics, hospitals, or pharmacies, and authorising multiple HCP roles to vaccinate pregnant women was key. In the US, access to influenza 
vaccination is generally convenient, and pregnant women are often immunised by obstetricians, gynecologists, or pharmacists [28]. In the UK and Spain, midwives accompany women throughout their pregnancy and therefore play a decisive role in driving awareness of the recommendations for vaccination [72, 82, 83]. A study in the Greater Manchester area in the UK highlighted the beneficial impact of coordinating GP surgeries with antenatal services, pharmacists, NHS foundation teams, and primary care trusts to maximize uptake among pregnant women. An effective electronic vaccine record and the allocation of adequate training resources to align messages across HCPs were found to be important components [84]. Initiatives such as text4baby in the US have also proved to be efficient calls to action to prompt pregnant women to get vaccinated $[85,86]$.

Regarding the accountability and engagement of HCPs (Pillar 3), a strong recommendation from an HCP is a clear driver of vaccine uptake for pregnant women as shown in multiple surveys from the US CDC [28, 38]. The mobilization of antenatal care professionals, such as obstetricians, gynecologists, and midwives is essential, given the importance of their advice for pregnant women and the multiple medical touchpoints during pregnancy. As such, in the US, the active endorsement of the ACIP recommendation by multiple HCP societies was crucial for the adoption of Tdap pregnancy vaccination [51]. Additionally, specific training and toolkits are produced and disseminated by the CDC and the ACOG to encourage obstetricians and gynecologists to vaccinate pregnant women [87-89]. In the UK, influenza and Tdap pregnancy vaccination is fully part of the contractual agreement between the health authorities and GPs, and includes the financial incentivization of vaccination in pregnancy ( $£ 10.06$ per immunisation in 2019$)$ as compensation for the obligation to record immunisation status, call and recall eligible individuals, and document active refusals [90].

Finally, awareness of the disease burden and belief in vaccination benefits are paramount to a successful programme (Pillars 4 and 5). The awareness of the burden of the disease relies on a well-established infectious disease surveillance network, whose epidemiological and clinical data can be used for research, public health decision making, and communication purposes [82]. The knowledge of the disease severity and vulnerability to the infection have an immediate effect on VCR as illustrated by the impact of the pertussis outbreaks in the UK and Spain at the inception of their respective programmes [59, 75, 76]. In the US, patient associations such as the California Immunisation Coalition have developed collections of stories to illustrate the burden of vaccine-preventable diseases such as pertussis.
Confidence in vaccine safety and vaccine effectiveness can nonetheless vary widely, especially for vaccination in pregnancy, depending on cultural, ethnic, and socioeconomic factors [77]. An active monitoring and responsiveness towards vaccine disinformation complemented by regular attitudinal surveys of the perceptions of both pregnant women and the HCPs who take care of them are essential to address misconceptions and tailor communication strategies [91-94].

While the benefits of pregnancy vaccination programmes are acknowledged by the public health community, increasing VCR remains a complex challenge which can often present an added level of difficulty for the vaccination of pregnant women given the persisting misconceptions on the safety of such interventions [36, 52, 95]. A large number of studies have gathered quantitative insights on the knowledge, attitudes, and practices of pregnant women and HCPs with the aim to suggest avenues for improvement [36, 69, 92, 96, 97]. However, few studies have isolated programmatic and policy directed interventions at the initiation of programmes that lead to high pregnancy vaccination uptakes for influenza or for Tdap [14, 98]. No previous studies have documented the experience of successful pregnancy vaccination programmes for influenza and pertussis across countries with different healthcare systems.

As such, this is the first study to describe the components of a successful pregnancy programme for both influenza and Tdap vaccinations across all the different stakeholders involved. These components are clustered in 5 pillars, providing a ready-to-use framework to complement the field guide developed by the WHO for Latin America and the WHO manual on the implementation of influenza vaccination of pregnant women [30, 99].

This analysis also provides a comprehensive framework to perform a situation assessment and identify policy and programmatic gaps hindering high VCR in pregnancy. Given the increasing number of countries issuing recommendations for vaccinating pregnant women, and the room for improvement in several existing programmes, including the three countries covered in this study, this analysis of best-in-class practices highlights key drivers for uptake. In the current context of the COVID-19 pandemic, some of the key learnings from this study could also be useful for scientific discussions and policy-making regarding COVID-19 VCR in pregnant women [77].

This study has several limitations. Firstly, the selection of the studied countries could have been widened to include other countries with well-established pregnancy vaccination programmes. For instance, surveys 
have been performed in Canada and Australia with the objective of identifying challenges regarding vaccination during pregnancy and strategies to overcome these issues $[100,101]$. Moreover, the three countries are examined from national perspective that does not take into account nuances and disparities across their regions or states. VCR estimation methods also vary from country to country with CDC data based on surveys for the US, while PHE data is based on GP reports, and Spanish data from reporting in each region. Furthermore, the adaptability of the framework to low- or middle-income countries is limited since only high-income countries were selected for this analysis. High-performing pregnancy vaccination programmes also exist in upper middle income countries such as Argentina and Mexico [102-104].

\section{Conclusions}

This study has shown that the components of successful pregnancy vaccination programmes can be analysed through five key pillars for success. Within each of these pillars a list of components that combine to drive vaccine uptake was identified, with the US, the UK and Spain each having their own specific combination of components contributing to high VCRs among pregnant women. The three studied countries show that a successful VCR does not necessarily require the implementation of all components; instead, the combination of components should be fine-tuned according to the specificities of the healthcare system in place and in consideration of the societal and cultural aspects of pregnancy vaccination. This framework can therefore serve as a guiding tool for public health experts, health authorities, and HCPs to identify the most relevant components for the successful implementation of a pregnancy vaccination programme that can be adapted to the local context.

\begin{abstract}
Abbreviations
ACIP: Advisory Committee on Immunisation Practices; ACOG: American College of Obstetricians and Gynecologists; AEP: Spanish Association of Paediatrics; CDC: Centers for Disease Control and Prevention; GMS: General Medical Service; GPs: General Practitioners; HA: Health authority; HCP: Healthcare professional; HPA: Health Protection Agency; JCVI: Joint Committee on Vaccination and Immunisation; KOLs: Key opinion leaders; NHS: National Health Service; PHE: Public Health England; RENAVE: Red Nacional de Vigilancia Epidemiológica; Tdap: Tetanus, diphtheria, acellular pertussis; UK: United Kingdom; US: United States; VCRs: Vaccine coverage rates; WHO: World Health Organization.
\end{abstract}

\section{Supplementary Information}

The online version contains supplementary material available at https://doi. org/10.1186/s12889-021-12198-2.

Additional file 1.

\section{Acknowledgements}

The manuscript received editorial support from a professional medical writer, Dr. Andrew Lane (Lane Medical Writing, France), funded by Sanofi Pasteur.

\section{Authors' contributions}

TB: Performed the comparative analysis across the countries studied, including the literature review and complementary desk research. Reviewed available evidence and adapted the 5-pillar framework and the list of components. Interpreted the findings, drafted, reviewed, and approved the manuscript. TRdF: Structured and performed the comparative analysis across the 3 high performing countries, sourced and reviewed the available evidence, and adapted the 5-pillar framework and the list of components. Interpreted the findings, structured the key messages, critically reviewed, and approved the manuscript. FB, OV and CK: Structured the comparative analysis, contributed to the interpretation of data, critically reviewed and approval the manuscript. LT, CEJ, ICE, MGS: Participated in data acquisition and analysis, reviewed, and approved the manuscript. All authors are accountable for the accuracy and integrity of the manuscript.

\section{Funding}

This work was funded by Sanofi Pasteur.

\section{Availability of data and materials}

All data generated or analysed during this study are included in this published article and its supplementary information files.

\section{Declarations}

Ethics approval and consent to participate

Following exchanges with editorial support at BMC, data from interviews performed prior to initiating this manuscript were removed given the absence of ethics committee review. The NHS Health Research Authority decision tool was initially used for this manuscript and suggested that an NHS Research Ethics Committees review was not needed for this study. However, BMC Public Health requires an ethics committee approval for interview data to be included. Removing the interviews does not significantly alter the results or discussion, as the data and knowledge were primarily collected through a combination of scientific literature review and desk research.

\section{Consent for publication}

Not applicable.

\section{Competing interests}

No author received any direct payment from Sanofi Pasteur with regards to their contributions to this manuscript but could have received expenses for the preliminary input collection and conference attendance for the presentation of data and results from this study.

$\mathrm{CK}$ and FB are employees of Sanofi Pasteur and may hold shares or stock options in the company.

TB, TRdeF and OV are employees of Corporate Value Associates (CVA). TB, TRdeF and OV report consultancy fees paid to CVA by Sanofi Pasteur, during the conduct of the study; and outside the submitted work.

CEJ reports personal fees from Sanofi Pasteur, during the conduct of the study: personal fees from MSD, personal fees from Pfizer, outside the submitted work. MGS reports personal fees from GSK, outside the submitted work.

ICE and LT have no conflicts of interest to disclose.

\section{Author details}

${ }^{1}$ CVA, London, UK. 2Sanofi Pasteur, 14, Espace Henry Vallée, 69007 Lyon, France. ${ }^{3}$ Asociación Nacional de Enfermería y Vacunas, Zaragoza, Spain. ${ }^{4}$ Hospital Quirónsalud Málaga, Málaga, Spain. ${ }^{5}$ Faculty of Medicine and Institute for Life Sciences University of Southampton and NIHR Southampton Clinical Research Facility and Biomedical Research Centre, University Hospital Southampton NHS Foundation Trust, Southampton, UK. ${ }^{6}$ CVA, Paris, France. ${ }^{7}$ Immunisation Action Coalition, Saint Paul, MN, USA.

Received: 3 May 2021 Accepted: 3 November 2021

Published online: 29 November 2021 


\section{References}

1. Baxter R, Bartlett J, Fireman B, Lewis E, Klein NP. Effectiveness of vaccination during pregnancy to prevent infant pertussis. Pediatrics. 2017; 139:20164091

2. Vygen-Bonnet S, Hellenbrand W, Garbe E, et al. Safety and effectiveness of acellular pertussis vaccination during pregnancy: a systematic review. BMC Infect Dis. 2020;20: 136. https://doi.org/10.1186/ s12879-020-4824-3.

3. Thompson MG, Li D-K, Shifflett P, Sokolow LZ, Ferber JR, Kurosky S, et al. Effectiveness of seasonal trivalent influenza vaccine for preventing influenza virus illness among pregnant women: a population-based case-control study during the 2010-2011 and 2011-2012 influenza seasons. Clin Infect Dis. 2014;58:449-57.

4. Thompson MG, Kwong JC, Regan AK, Katz MA, Drews SJ, AzzizBaumgartner $\mathrm{E}$, et al. Influenza vaccine effectiveness in preventing influenza-associated hospitalizations during pregnancy: a multi-country retrospective test negative design study, 2010-2016. Clin Infect Dis. 2019;68:1444-53.

5. Fell DB, Azziz-Baumgartner E, Baker MG, Batra M, Beauté J, Beutels P, et al. Influenza epidemiology and immunization during pregnancy: final report of a World Health Organization working group. Vaccine. 2017;35:5738-50.

6. World Health Organization. WHO SAGE Seasonal Influenza Vaccination Recommendations during the COVID-19 Pandemic. 2020. https://www. who.int/immunization/policy/position_papers/Interim_SAGE_influ enza_vaccination_recommendations.pdf. Accessed 12 Oct 2021.

7. Masseria C, Martin CK, Krishnarajah G, Becker LK, Buikema A, Tan TQ. Incidence and burden of pertussis among infants less than 1 year of age. Pediatr Infect Dis J. 2017;36:54-61

8. Kandeil W, Atanasov P, Avramioti D, Fu J, Demarteau N, Li X. The burden of pertussis in older adults: what is the role of vaccination? A systematic literature review. Expert Rev Vaccines. 2019;18:439-55.

9. Centers for Disease Control and Prevention. 2018 final pertussis surveillance Report. 2018.

10. Yeung KHT, Duclos P, Nelson EAS, Hutubessy RCW. An update of the global burden of pertussis in children younger than 5 years: a modelling study. Lancet Infect Dis. 2017;17:974-80

11. World Health Organization. Wkly Epidemiol Rec. 2005;33:277-88.

12. World Health Organization. Vaccines against influenza WHO position paper - November 2012. 2012

13. World Health Organization. Influenza immunization: Guidance to inform introduction of influenza vaccine in low and middle-income countries. 2019. https://www.who.int/teams/immunization-vaccinesand-biologicals/diseases/seasonal-influenza/guidance-intro-vaccinemic. Accessed 12 Oct 2021.

14. Buchy P, Badur S, Kassianos G, Preiss S, Tam JS. Vaccinating pregnant women against influenza needs to be a priority for all countries: an expert commentary. Int J Infect Dis. 2020;92:1-12.

15. Vojtek I, Dieussaert I, Doherty TM, Franck V, Hanssens L, Miller J, et al. Maternal immunization: where are we now and how to move forward? Ann Med. 2018:50:193-208.

16. Rizzo C, Rezza G, Ricciardi W. Strategies in recommending influenza vaccination in Europe and US. Hum Vaccin Immunother. 2018;14:693-8.

17. World Health Organization Europe. The WHO regional Office for Europe Evaluation of seasonal influenza vaccination policies and coverage in the WHO European Region. 2014.

18. Descamps A, Launay O, Bonnet C, Blondel B. Seasonal influenza vaccine uptake and vaccine refusal among pregnant women in France: results from a national survey. Hum Vaccines Immunother. 2020;16:1093-100.

19. Prospero E, Galmozzi S, Paris V, Felici G, Barbadoro P, D'Alleva A, et al. Factors influencing refusing of flu vaccination among pregnant women in Italy: healthcare workers' role. Influenza Other Respir Viruses. 2019;13:201-7.

20. Schulz M, Dammertz L, Doi BG. Impfung gegen saisonale Influenza in der Schwangerschaft gemäß STIKO-Empfehlung; 2017.

21. The Council of the European Union. Council recommendation of 22 December 2009 on seasonal influenza vaccination. 2009. https://eurlex.europa.eu/LexUriServ/LexUriServ.do?uri=OJ:L:2009:348:0071:0072: EN:PDF. Accessed 12 Oct 2021

22. European Centre for Disease Prevention and Control (ECDC). Influenza vaccination coverage rates insufficient across EU Member States. 2018. https:// www.ecdc.europa.eu/en/news-events/influenza-vaccination-coveragerates-insufficient-across-eu-member-states. Accessed 12 Oct 2021.

23. World Health Organisation. Pertussis vaccines: WHO position paper September 2015. 2015.

24. Figueroa JP, Andrus JK, Bonvehi P, Glass R, Homma A, King A, et al. Twenty-fifth meeting of the technical advisory group (TAG) on vaccinepreventable diseases. Cartagena; 2019. https://www3.paho.org/hq/ index.php?option =com_docman\&view =download\&alias $=50491-25$ tag-final-report-2019\&category_slug=tag-final-reports-1626\&ltemid= 270\&lang=pt. Accessed 12 Oct 2021

25. Abu-Raya B, Maertens K, Edwards KM, et al. Global Perspectives on Immunization During Pregnancy and Priorities for Future Research and Development: An International Consensus Statement. Front Immunol. 2020;11:1282. https://doi.org/10.3389/fimmu.2020.01282.

26. Ministerio de Sanidad Consumo y Bienestar Social. Spain. Coberturas de vacunación con dTpa en embarazadas. Comunidades autónomas. Años 2017 y 2018. 2019.

27. Public Health England. Pertussis vaccination programme for pregnant women: vaccine coverage in England, January to March 2020 and 2019-20 annual coverage. 2020

28. Centers for Disease Control and Prevention. Pregnant Women and Tdap Vaccination, Internet Panel Survey. https://www.cdc.gov/vaccines/ pregnancy/hcp-toolkit/tdap-report.html. Accessed 12 Oct 2021.

29. Kahn KE, Black CL, Ding H, Williams WW, Lu P-J, Fiebelkorn AP, et al. Influenza and Tdap vaccination coverage among pregnant women — United States, April 2018. MMWR Morb Mortal Wkly Rep. 2018:67:1055-9.

30. World Health Organization. Maternal and neonatal immunization field guide for Latin America and the Caribbean. 2017. https://www.paho. org/en/documents/maternal-and-neonatal-immunization-field-guidelatin-america-and-caribbean.

31. World Health Organization. Influenza Vaccine Post-Introduction Evaluation (IPIE) 2020

32. World Health Organization. Report of the SAGE Working Group on Vaccine Hesitancy. 2014. https://www.who.int/immunization/sage/meet ngs/2014/october/1_Report_WORKING_GROUP_vaccine_hesitancy_ final.pdf. Accessed 12 Oct 2021

33. Thomson A, Robinson K, Vallée-Tourangeau G. The 5As: a practical taxonomy for the determinants of vaccine uptake. Vaccine. 2016:34:1018-24

34. Kassianos G, Banerjee A, Baron-Papillon F, Hampson AW, McElhaney JE, McGeer A, et al. Key policy and programmatic factors to improve influenza vaccination rates based on the experience from four highperforming countries. Drugs Context. 2021;9:1-13.

35. Park N. Population estimates for the UK, England and Wales, Scotland and Northern Ireland - Office for National Statistics. ONS. 2018;8 https:// www.ons.gov.uk/peoplepopulationandcommunity/populationandmi gration/populationestimates/bulletins/annualmidyearpopulationes timates/latest. Accessed 12 Oct 2021.

36. Wilcox CR, Calvert A, Metz J, Kilich E, MacLeod R, Beadon K, et al. Determinants of influenza and pertussis vaccination uptake in pregnancy a multicenter questionnaire study of pregnant women and healthcare professionals. Pediatr Infect Dis J. 2019;38:625-30.

37. Kennedy ED, Ahluwalia IB, Ding H, Lu PJ, Singleton JA, Bridges CB. Monitoring seasonal influenza vaccination coverage among pregnant women in the United States. Am J Obstet Gynecol. 2012;207(3 SUPPL):S9-16.

38. Ding $H$, Black CL, Ball S, Fink RV, Williams WW, Fiebelkorn AP, et al. Influenza vaccination coverage among pregnant women - United States, 2016-17 influenza season. MMWR Morb Mortal Wkly Rep. 2017:66:1016-22.

39. Centers for Disease Control and Prevention. Prevention and Control of Influenza Recommendations of the Advisory Committee on Immunization Practices. MMWR. 1995;44 RR-03:1-22.

40. Centers for Disease Control and Prevention. Prevention and Control of Influenza: Recommendations of the Advisory Committee on Immunization Practices (ACIP). MMWR. 1997:46 RR-09:1-25.

41. Centers for Disease Control. Prevention and control of influenza: part I, vaccines recommendations of the advisory committee on immunization practices. MMWR. 1994;43:1-13.

42. World Health Organization. Wkly Epidemiol Rec. 2004;79:13-24. 
43. Centers for Disease Control and Prevention. Prevention and control of influenza: recommendations of the advisory committee on immunization practices (ACIP). MMWR. 2004:53:1-40.

44. American College of Obstetricians and Gynecologists Committee on Obstetric Practice. ACOG committee opinion number 305, November 2004. Influenza vaccination and treatment during pregnancy. Obstet Gynecol. 2004;104:1125-6.

45. Rasmussen SA, Jamieson DJ. 2009 H1N1 influenza and Pregnancy-5 years later. N Engl J Med. 2014;15:371.

46. Healthy People 2020. Immunization and Infectious Diseases - 12.14 Data Details | Healthy People 2020. https://www.healthypeople.gov/ node/6362/data_details. Accessed 12 Oct 2021.

47. Razzaghi H, Kahn KE, Black CL, Lindley MC, Jatlaoui TC, Fiebelkorn AP, et al. Influenza and Tdap vaccination coverage among pregnant women - United States, April 2020. MMWR Morb Mortal Wkly Rep. 2020;69:1391-7.

48. Winter K, Zipprich J, Harriman K. Pertussis in California: a tale of 2 epidemics. Pediatr Infect Dis J. 2018;37:324-8. https://doi.org/10.1097/INF. 0000000000001761

49. Centers for Disease Control and Prevention (CDC). Updated Recommendations for Use of Tetanus Toxoid, Reduced Diphtheria Toxoid and Acellular Pertussis Vaccine (Tdap) in Pregnant Women - Advisory Committee on Immunization Practices (ACIP), 2012. MMWR Morb Mortal Wkly Rep. 2013;62:131-5.

50. Centers for Disease Control and Prevention. Updated Recommendations for Use of Tetanus Toxoid, Reduced Diphtheria Toxoid and Acellular Pertussis Vaccine (Tdap) in Pregnant Women and Persons Who Have or Anticipate Having Close Contact with an Infant Aged $<12$ Months --- Advisory Committee on Immuniza. MMWR. 2011:60:1424-6.

51. American College of Obstetricians and Gynecologists. Committee Opinion No. 566: Update on Immunization and Pregnancy Tetanus, Diphtheria, and Pertussis Vaccination. Obstet Gynecol. 2013;121:1411-4.

52. Strassberg ER, Power M, Schulkin J, Stark LM, Mackeen AD, Murtough $\mathrm{KL}$, et al. Patient attitudes toward influenza and tetanus, diphtheria and acellular pertussis vaccination in pregnancy. Vaccine. 2018:36:4548-54.

53. Public Health England. Vaccine uptake guidance and the latest coverage data - GOV.UK. https://www.gov.uk/government/collections/vacci ne-uptake\#seasonal-flu-vaccine-uptake:-figures. Accessed 12 Oct 2021.

54. Public Health England. Immunisation against infectious disease: The Green Book. 2019. https://www.gov.uk/government/publications/influ enza-the-green-book-chapter-19.

55. Knight M, Kenyon S, Brocklehurst P, Neilson J, Shakespeare J, Kurinczuk J. Saving lives, improving mothers' care lessons learned to inform future maternity care from the UK and Ireland confidential enquiries into maternal deaths and morbidity 2009-2012. 2014. https://www.npeu.ox. ac.uk/assets/downloads/mbrrace-uk/reports/Saving/Lives/Improving/ Mothers/Care report/2014/Full.pdf.

56. Jit M, Cromer D, Baguelin M, Stowe J, Andrews N, Miller E. The costeffectiveness of vaccinating pregnant women against seasonal influenza in England and Wales. Vaccine. 2010;29:115-22.

57. Eaton Turner E, Claxton L, Taylor M. National Institute for Health And Care Excellence Flu Vaccination: Increasing Uptake Final Report. 2017 https://yhec.co.uk/wp-content/uploads/2020/12/economic-modellingreport-pdf-6532084909.pdf. Accessed 12 Oct 2021.

58. Public Health England. Laboratory confirmed cases of pertussis in England. 2019. https://assets.publishing.service.gov.uk/government/uploa ds/system/uploads/attachment_data/file/881380/hpr0820_PRTSSS_ annual.pdf.

59. Gov.UK. Pregnant women to be offered whooping cough vaccination. 2012. https://www.gov.uk/government/news/pregnant-women-to-beoffered-whooping-cough-vaccination.

60. Whooping cough: three more babies die in outbreak. British Broadcasting Corporation (BBC) News. 2012. https://www.bbc.co.uk/news/ health-20539837\#: :text=Three/babies/died/from/whooping,compl ications\%2C/to/13/this/year.

61. Whooping cough cases highest for 18 years: Health Protection Agency. The Telegraph. 2012. https://www.telegraph.co.uk/news/health/news/ 9511931/Whooping-cough-cases-highest-for-18-years-HPA.html.

62. Joint Committee on Vaccination and Immunisation. Minute of teleconference on 30 August 2012. 2012.
63. Public Health England. Pertussis vaccination programme for pregnant women update: vaccine coverage in England, October to December 2019 health protection report. 2020;14(4):14.

64. Joint Committee on Vaccination and Immunisation. Minute of the meeting on 4 June 2014. 2014.

65. Joint Committee on Vaccination and Immunisation. Minute of the meeting on 3 February 2016. 2016.

66. Rodríguez-Blanco N. Maternidad y vacunas: análisis de la aceptabilidad y cobertura vacunal para gripe y tos ferina en gestantes de dos Departamentos de Salud de la Comunidad Valenciana durante la temporada 2015-2016: Universidad de Alicante; 2018.

67. Vilca Yengle LM, Campins Martí M, Cabero Roura L, Rodrigo Pendás JÁ, Martínez Gómez X, Hermosilla Pérez E, et al. Vacunación antigripal en gestantes. Cobertura vacunal y conocimientos y prácticas de los obstetras. Med Clin (Barc). 2010;134:146-51.

68. Generalitat de Catalunya Departament de Salut. Manual de Vacunacions. 4th ed. Barcelona; 2006. https://salutpublica.gencat.cat/web/ content/minisite/aspcat/promocio salut/vacunacions/00manual_de vacunacions/Manual-de-vacunacions.pdf. Accessed 12 Oct 2021

69. Vilca LM, Verma A, Buckeridge D, Campins M. A population-based analysis of predictors of influenza vaccination uptake in pregnant women: the effect of gestational and calendar time. Prev Med (Baltim). 2017;99:111-7.

70. Ministerio de Sanidad Consumo y Bienestar Social. Spain. Vacunas Coberturas de Vacunación. https://www.mscbs.gob.es/profesionales/ saludPublica/prevPromocion/vacunaciones/calendario-y-coberturas/ coberturas/home.htm. Accessed 12 Oct 2021

71. Generalitat Valenciana Conselleria De Sanitat Universal I Salut Publica. Spain. Prevencion y Vigilancia de la Gripe Informes De Salud. Spain. http://publicaciones.san.gva.es/. Accessed 14 Oct 2021

72. Rodríguez-Blanco N, Tuells J, Vila-Candel R, Nolasco A. Adherence and concordance of influenza and pertussis vaccination coverage in pregnant women in Spain. Int J Environ Res Public Health. 2019;16:1-12.

73. Ministerio De Sanidad Consumo Y Bienestar Social. Spain. Recomendaciones de vacunación frente a la gripe Temporada 2018-2019. 2018. https://www.mscbs.gob.es/profesionales/saludPublica/prevPromoc ion/vacunaciones/programasDeVacunacion/gripe/Historico_Recom endacionesVacunacion.htm.

74. de Viarce Torres de Mier M, López-Perea N, Masa Calles J. Pertussis in Spain, 1998-2016 Preliminary Impact of pertussis vaccination program on pregnant women. 2018.

75. Campins M, Moreno-Pérez D, Gil-De Miguel A, González-Romo F, Moraga-Llop FA, Arístegui-Fernández J, et al. Tos ferina en España. Situación epidemiológica y estrategias de prevención y control. Recomendaciones del Grupo de Trabajo de Tos ferina. Enferm Infecc Microbiol Clin. 2013;31:240-53.

76. Comité Asesor de Vacunas. SPAIN. Tosferina : la importancia de la vacunación de la embarazada. 2015. https://vacunasaep.org/sites/vacun asaep.org/files/cav-aep-tosferina-embarazada_0.pdf.

77. de la Cruz CM, Encinas Pardilla M, Garcia Sanchez M, Gonzalez Rodriguez L, Muner-Hernando M, Royuela Vicente A, et al. Impact of recommended maternal vaccination programs on the clinical presentation of SARS-CoV-2 infection: a prospective observational study. Vaccines. 2021;9:31.

78. Amirthalingam G, Letley L, Campbell H, Green D, Yarwood J, Ramsay M. Lessons learnt from the implementation of maternal immunization programs in England. Hum Vaccines Immunother. 2016;12:2934-9.

79. American Academy of Family Physicians, American College of NurseMidwives, American College of Obstetricians and Gynecologists, Association of Women's health obstetric and neonatal nurses. MATERNAL IMMUNIZATION TASK FORCE - Immunization for Pregnant Women: A Call to Action. 2020

80. National Foundation for Infectious Diseases. Improving Vaccination Rates in Pregnant Women: Timely intervention-lasting benefits Call to Action. 2014. https://www.nfid.org/publications/improving-vacci nation-rates-in-pregnant-women-2014/. Accessed 12 Oct 2021.

81. Spanish Ministry of Health Social Services and Equality. Clinical Practice Guideline for Care in Pregnancy and Puerperium. 2014.

82. Ford AJ, Alwan NA. Use of social networking sites and women's decision to receive vaccinations during pregnancy: a cross-sectional study in the UK. Vaccine. 2018:36:5294-303. 
83. Clarke RM, Paterson P, Sirota M. Determinants of satisfaction with information and additional information-seeking behaviour for the pertussis vaccination given during pregnancy. Vaccine. 2019;37:2712-20.

84. Baxter D. Approaches to the vaccination of pregnant women: experience from Stockport, UK, with prenatal influenza. Hum Vaccines Immunother. 2013;9:1360-3.

85. Jordan ET, Bushar JA, Kendrick JS, Johnson P, Wang J. Encouraging influenza vaccination among text4baby pregnant women and mothers. Am J Prev Med. 2015:49:563-72.

86. Bushar JA, Kendrick JS, Ding H, Black CL, Greby SM. Text4baby influenza messaging and influenza vaccination among pregnant women. Am J Prev Med. 2017:53:845-53.

87. Centers for Disease Control and Prevention. Pregnancy and Vaccination: Prenatal Care Providers Toolkit. https://www.cdc.gov/vaccines/pregn ancy/hcp-toolkit/index.html.

88. American College of Obstetricians and Gynecologists. Physician Tools. https://www.acog.org/programs/immunization-for-women/physiciantools. Accessed 12 Oct 2021

89. Jones KM, Carroll S, Hawks D, McElwain CA, Schulkin J. Efforts to improve immunization coverage during pregnancy among Ob-Gyns. Infect Dis Obstet Gynecol. 2016;2016.

90. National Health Service (NHS) England. Enhanced Service Specification Pertussis (pregnant women) vaccination programme 2020/21. 2019 https://www.england.nhs.uk/wp-content/uploads/2020/03/20-21VI003-pertussis-final-version-004.pdf.

91. Vishram B, Letley L, Jan Van Hoek A, Silverton L, Donovan H, Adams $C$, et al. Vaccination in pregnancy: attitudes of nurses, midwives and health visitors in England. Hum Vaccines Immunother. 2018;14:179-88

92. Vilca LM, Martínez C, Burballa M, Campins M. Maternal care providers' barriers regarding influenza and pertussis vaccination during pregnancy in Catalonia. Spain Matern Child Health J. 2018:22:1016-24.

93. King JP, Hanson KE, Donahue JG, Glanz JM, Klein NP, Naleway AL, et al. Survey of influenza vaccine knowledge, attitudes, and beliefs among pregnant women in the 2016-17 season. Vaccine. 2020;38:2202-8.

94. Ellingson M, Chamberlain AT. Beyond the verbal: pregnant women's preferences for receiving influenza and Tdap vaccine information from their obstetric care providers. Hum Vaccines Immunother. 2018;14:767-71.
95. Vila-Candel R, Navarro-Illana P, Navarro-IIlana E, Castro-Sánchez E, Duke $\mathrm{K}$, Soriano-Vidal FJ, et al. Determinants of seasonal influenza vaccination in pregnant women in Valencia, Spain. BMC Public Health. 2016;16:1-7.

96. O'Leary ST, Riley LE, Lindley MC, Allison MA, Crane LA, Hurley LP, et al. Immunization practices of U.S. obstetrician/gynecologists for pregnant patients. Am J Prev Med. 2018;54:205-13.

97. Mehrotra A, Fisher AK, Mullen J, Rodriguez L, Jiles AJ, Albert AP, et al. Provider insight on surmounting specialty practice challenges to improve Tdap immunization rates among pregnant women. Heliyon. 2018:4:e00636

98. MacDougall DM, Halperin SA. Improving rates of maternal immunization: challenges and opportunities. Hum Vaccines Immunother. 2016:12:857-65.

99. World Health Organization. How to implement influenza vaccination of pregnant women. 2017. http://apps.who.int/iris/bitstream/handle/ 10665/250084/WHO-IVB-16.06-eng.pdf.

100. Dubé E, Gagnon D, Kaminsky K, Green CR, Ouakki M, Bettinger JA, et al. Vaccination against influenza in pregnancy: a survey of Canadian maternity care providers. J Obstet Gynaecol Canada. 2019;41:479-88.

101. Mohammed H, Clarke M, Koehler A, Watson M, Marshall H. Factors associated with uptake of influenza and pertussis vaccines among pregnant women in South Australia. PLOS ONE . 2018;13(6):e0197867. https://doi. org/10.1371/journal.pone.0197867.

102. Neyro S, Katz N, Biscayart C, Juarez MDV, Stecher D, Aquino A, et al. Maternal immunization in Argentina: Nationwide strategy. Int J Infect Dis. 2018;73:176. https://doi.org/10.1016/J.IJID.2018.04.3813.

103. Guzman-Holst A, Luna-Casas G, Cervantes-Apolinar MY, Huerta-Garcia GC, Juliao P, Sánchez-González G. Pertussis infant morbidity and mortality trends after universal maternal immunisation in Mexico: an ecological database study with time-series analysis. Vaccine. 2021;39:2311-8.

104. Ropero-Álvarez AM, El ON, Kurtis HJ, Danovaro-Holliday MC, Ruiz-Matus C. Influenza vaccination in the Americas: Progress and challenges after the 2009 a(H1N1) influenza pandemic. Hum Vaccin Immunother. 2016;12:2206. https://doi.org/10.1080/21645515.2016.1157240.

\section{Publisher's Note}

Springer Nature remains neutral with regard to jurisdictional claims in published maps and institutional affiliations.
Ready to submit your research? Choose BMC and benefit from:

- fast, convenient online submission

- thorough peer review by experienced researchers in your field

- rapid publication on acceptance

- support for research data, including large and complex data types

- gold Open Access which fosters wider collaboration and increased citations

- maximum visibility for your research: over $100 \mathrm{M}$ website views per year

At BMC, research is always in progress.

Learn more biomedcentral.com/submissions 